\title{
Stabilization of a Residual Soil Using Calcium and Magnesium Hydroxide Nanoparticles: A Quick Precipitation Method
}

\author{
Lee Li Yong ${ }^{1}$, S.V.A.D. Namal Jayasanka Perera ${ }^{1}$, Agusril Syamsir ${ }^{2}$, Endene Emmanuel ${ }^{1}$, \\ Suvash Chandra Paul ${ }^{1,3}$ (1) and Vivi Anggraini ${ }^{1, * \mathbb{C}}$ \\ 1 Civil Engineering Discipline, School of Engineering, Monash University Malaysia, Jalan Lagoon Selatan, \\ Bandar Sunway 47500, Selangor, Malaysia; LeeLi.Yong@monash.edu (L.L.Y.); \\ njsom1@student.monash.edu (S.V.A.D.N.J.P.); emmanuel.endeneche@monash.edu (E.E.); \\ suvashpl@iubat.edu (S.C.P.) \\ 2 Institute of Energy Infrastructure (IEI), Universiti Tenaga Nasional, Jalan Ikram-Uniten, Kajang 43000, \\ Selangor, Malaysia; Agusril@uniten.edu.my \\ 3 Department of Civil Engineering, International University of Business Agriculture and Technology, \\ Dhaka 1230, Bangladesh \\ * Correspondence: vivi.anggraini@monash.edu
}

Received: 9 September 2019; Accepted: 10 October 2019; Published: 15 October 2019

\begin{abstract}
The current study examines the potential of using calcium and magnesium hydroxide nanoparticles synthetized through a quick precipitation method as soil stabilizers for improving the engineering properties of tropical residual soil. The engineering properties of untreated and nanoparticles-treated soil were studied by carrying out a series of geotechnical tests including compaction, Atterberg limits, falling head permeability, and unconfined compressive strength (UCS). The stabilization mechanisms associated with soil-chemical reactions were further explored by performing microstructural analyses such as x-ray diffraction (XRD), variable-pressure scanning electron microscope (VP-SEM), and energy-dispersive x-ray spectroscopy (EDX). The findings revealed that the calcium hydroxide and magnesium hydroxide nanoparticles improved the geotechnical properties of residual soils in terms of reduced hydraulic conductivity and increased UCS. The percentage reduction of the hydraulic conductivity of magnesium and calcium hydroxide nanoparticles-treated soils compared to untreated soil after seven weeks of permeation were $85.14 \%$ and $98.70 \%$, respectively. The magnesium and calcium hydroxide nanoparticles-treated soils subjected to 14 days of curing recorded a percentage increase in the UCS of $148.05 \%$ and $180.17 \%$, respectively compared to untreated soil. Hence, it can be concluded that both magnesium and calcium hydroxide nanoparticles can be effectively utilized as environmental-friendly stabilizers.
\end{abstract}

Keywords: soil stabilization; nanoparticles; quick precipitation method; residual soils; geotechnical characterization; microstructural characterization

\section{Introduction}

Residual soils are the products of in situ rock weathering induced by the interaction of natural feature such as environmental conditions and chemical compositions of the parent rock over an extended period. The high temperatures and heavy rainfalls in tropical regions contribute significantly to the intense rock weathering process and favor the formation of tropical residual soils [1]. Tropical residual soils constitute three-quarters of the land area in Malaysia, which is well known for its humid tropical climate [2]. The predominance of chemical weathering in tropical regions which occurs gradually over time results in the formation of iron oxides/hydroxides and fine-grained clay 
minerals [3]. The significant percentage of silt and clay present in the tropical residual soil deposits may cause the soils to experience poor engineering properties [4,5]. Hence, soil stabilization is required to improve the engineering properties of such tropical residual soils prior to their application in various construction works.

Calcium-based additives such as cement and lime stand as the most popular and commonly used soil stabilization materials due to their robustness and easy adaptability to various soil types [6]. Moreover, their availability in various parts of the globe is also an added advantage. The mechanism of soil stabilization using calcium-based additives is mainly attributed to the formation of cementing gels such as calcium aluminate hydrates (C-A-H) and calcium silicate hydrates (C-S-H) associated with the reactions between the calcium ions and clay minerals [7]. Previous studies have demonstrated that calcium-treated soils showed improved engineering properties such as increased shear strength and reduced hydraulic conductivity, shrinkage, and swelling limits [8]. However, the cost of production for cement and lime is relatively expensive, and the carbon dioxide emission during their production poses environmental concerns $[9,10]$. Consequently, these concerns have motivated the exploration of environmentally friendly, cost-effective, and efficient materials that exhibit similar cementing properties as calcium-based additives.

Nanotechnology refers to the utilization of nanoscale materials with dimensions smaller than $100 \mathrm{~nm}$ [11]. The nature-friendly nanomaterials, which are characterized by their fine particle size, high specific surface area, and high reactivity, can cause significant improvements to the engineering properties of poor soil [12]. In recent years, nanotechnology has been gaining momentum ever since the successful application of various nanomaterials in soil stabilization. Changizi and Haddad [13] reported that the addition of nano-silicon dioxide and recycled polyester fiber increased the elastic modulus, unconfined compressive strength (UCS), and shear strength of the soft clay. Coo et al. [14] indicated that the inclusion of nanoparticles in kaolin clay led to an increase in the shrinkage limit and a reduction in the total volume of the treated clay. Iranpour and Haddad [11] indicated that four types of nanomaterials such as nanoclay, nanocopper, nanoalumina, and nanosilica showed different effects on the engineering properties of collapsible soils. Alsharef et al. [15] also investigated the effects of nanocarbons on the Atterberg limits, compaction characteristics, specific gravity, $\mathrm{pH}$, and hydraulic conductivity of Malaysian residual soils. They concluded that the presence of nanocarbons in residual soil caused an increment in $\mathrm{pH}$ values and a reduction in their plasticity index, compaction characteristics, specific gravity, and hydraulic conductivity. Naval et al. [16] reported a significant reduction in the swelling potential and improved workability of an expansive soil treated with nano magnesium oxide and nano alumina.

Nanoparticles can be synthesized mainly by two methods, which are (i) the bottom-up method which refers to the formation of nanoparticles from atoms and molecular clusters in liquid or vapor phase, and (ii) the top-down method, which involves the process of breaking up bulk materials into nanoscale particles [17]. The quick precipitation method is an example of a bottom-up method that has received great attention due to its simplicity, cost-effectiveness, and ease of mass production $[18,19]$. Several researchers have adopted quick precipitation in the synthetization of different nanomaterials such as (i) nano copper oxide [19-21], (ii) nano iron oxide [22,23], (iii) nano ferric hydroxide and nano aluminum hydroxide [24], and (iv) nano calcium hydroxide and nano magnesium hydroxide [18] in various applications. However, to the best of the authors' knowledge, limited to no studies have utilized nanoparticles prepared using the quick precipitation method in soil stabilization.

Addressing the above-mentioned gap, this study aimed at exploring the feasibility of using magnesium and calcium hydroxide nanoparticles prepared using a quick precipitation method for improving the geotechnical properties of a tropical residual soil. To this end, a series of geotechnical tests, including Atterberg limits, compaction, hydraulic conductivity, and UCS were conducted to study the effects of magnesium and calcium hydroxide nanoparticles on the engineering properties of a residual soil. Moreover, the changes occurring in the soil engineering properties were examined by performing microstructural tests including: X-ray diffraction (XRD), energy-dispersive $x$-ray 
spectroscopy (EDX), and variable-pressure scanning electron microscope (VP-SEM). Finally, descriptive statistics were employed to better assess the effect of magnesium and calcium hydroxide nanoparticles treatments on the UCS development.

\section{Materials and Methodology}

\subsection{Residual Soil}

Residual soil samples used in the current study were collected from a construction site at Bukit Tunku, Kuala Lumpur, Malaysia. The construction site lies around longitudinal $3^{\circ} 10^{\prime} 13.1^{\prime \prime} \mathrm{N}$ and latitude $101^{\circ} 41^{\prime} 10.5^{\prime \prime} \mathrm{E}$ that is underlain by Kenny Hill Formation, which comprises of phyllite, quartzite, and schist with a minor intercalation of limestone [25]. A shovel was used to excavate the soil sample from a depth of $0.5 \mathrm{~m}$ below the ground surface. Then, the collected samples were bagged and transported to the laboratory for investigation. The particle size distribution of the obtained soil samples is shown in Figure 1. As shown in Figure 1, the obtained soil samples were dominated by $64.8 \%$ of fine fractions ( $25.3 \%$ of silt and $39.5 \%$ of clay), $34.63 \%$ of sand, and $0.57 \%$ of gravel.

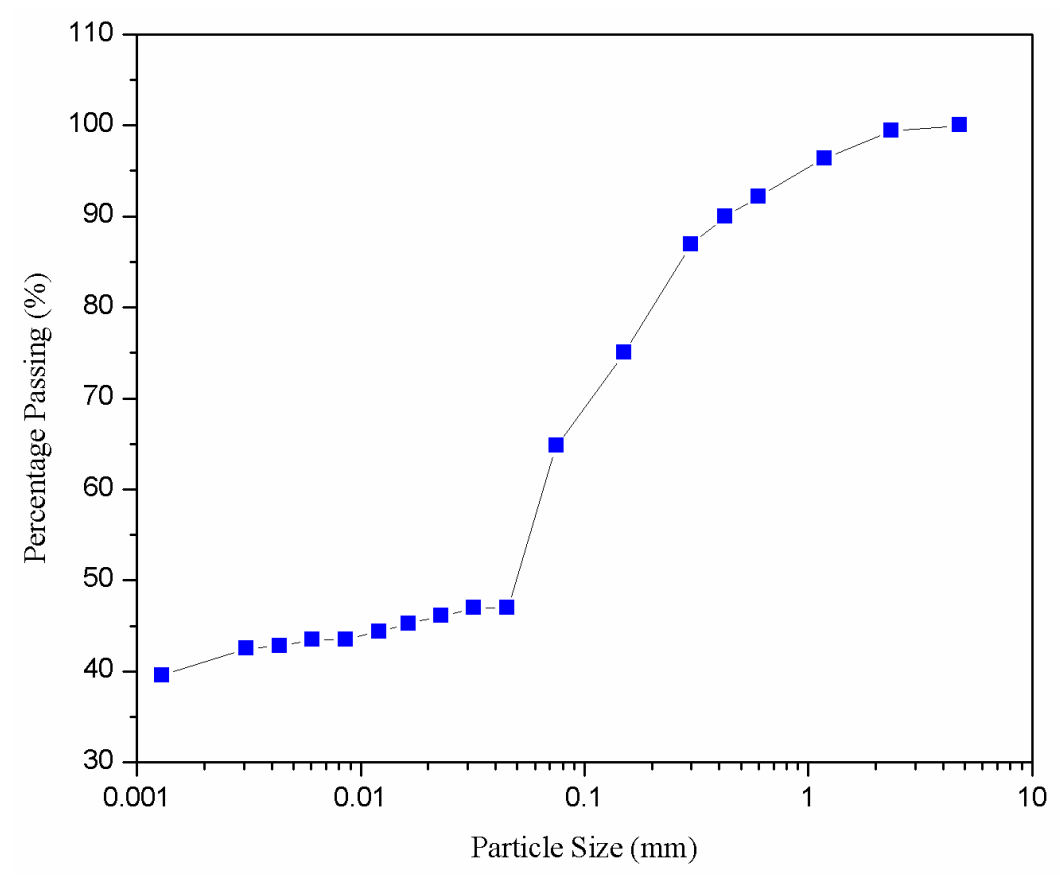

Figure 1. Particle size distribution curve of the natural soil.

\subsection{Soil Sample Preparation}

The collected soil samples were first oven-dried for $24 \mathrm{~h}$ at $105^{\circ} \mathrm{C}$. The oven-dried soils were then crushed into smaller particles using a pestle and mortar and sieved through 4.75-mm and 425- $\mu \mathrm{m}$ sieves. Soil samples that passed through the $4.75-\mathrm{mm}$ sieve were used to carry out a standard Proctor compaction test, hydraulic conductivity test, and UCS test. On the other hand, soil samples that passed through a $425-\mu \mathrm{m}$ sieve were used to conduct Atterberg limits and a specific gravity test.

\subsection{Nanoparticles Preparation}

Two nanoparticles, namely the (i) calcium hydroxide nanoparticles $\left(\mathrm{Ca}(\mathrm{OH})_{2}\right)$ and (ii) magnesium hydroxide nanoparticles $\left(\mathrm{Mg}(\mathrm{OH})_{2}\right)$ used in this study, were prepared using the quick precipitation method. First, $0.5 \mathrm{M} \mathrm{CaCl}_{2}$ were prepared and mixed with $0.5 \mathrm{M} \mathrm{NaOH}$ solutions at room temperature. The chemical reactions between calcium chloride and sodium hydroxide triggered the precipitation of $\mathrm{Ca}(\mathrm{OH})_{2}$ nanoparticles in the mixed solutions. Then, the prepared solutions were mixed with the crushed soil samples and subjected to further geotechnical tests. The concentration of $0.5 \mathrm{M}$ of 
solutions was considered in this study, as this concentration was noted as an optimum concentration for reinforcing coir fibers $[18,24]$. The same procedures reported above were repeated to prepare the magnesium hydroxide nanoparticles $\left(\mathrm{Mg}(\mathrm{OH})_{2}\right)$ using $0.5 \mathrm{M} \mathrm{MgCl}_{2}$ and $0.5 \mathrm{M} \mathrm{NaOH}$ solutions. The chemical reactions involved in the quick precipitation methods are shown in Equations (1) and (2) for the calcium hydroxide nanoparticles and magnesium hydroxide nanoparticles, respectively:

$$
\begin{gathered}
\mathrm{CaCl}_{2}+2 \mathrm{NaOH} \rightarrow \mathrm{CaOH}_{2}+2 \mathrm{NaCl} \\
\mathrm{MgCl}_{2}+2 \mathrm{NaOH} \rightarrow \mathrm{MgOH}_{2}+2 \mathrm{NaCl}
\end{gathered}
$$

\subsection{Geotechnical Tests}

\subsubsection{Particle Size Distribution, Atterberg Limits, and Specific Gravity}

The methods stipulated in [26] were followed to carry out the wet sieving and a hydrometer sedimentation test for the determination of the particle size distribution of the natural soil. Atterberg limits for the natural and treated soil specimens were examined based on the procedures stated in [26]. The cone penetrometer method was adopted to obtain the liquid limit of the soil sample. The specific gravity of soil sample was determined according to the small pycnometer method outlined in [26].

\subsubsection{Standard Proctor Compaction}

The compaction characteristics of the untreated and nanoparticle-treated residual soils samples were investigated by conducting the standard Proctor compaction test using a $2.5-\mathrm{kg}$ metal rammer dropped from a height of $30 \mathrm{~cm}$, as outlined in [26]. The soil samples were first mixed manually at a different range of water contents and cured for $24 \mathrm{~h}$ before performing the compaction test. Then, the prepared soil samples were compacted in three layers with each layer receiving 27 blows. The compaction characteristics of the untreated and nanoparticles-treated soil samples were determined from the graph portraying the relationship between the dry density and moisture content of the soil samples.

\subsubsection{Hydraulic Conductivity}

The falling head hydraulic conductivity tests were conducted according to the methodology defined in [27] to investigate the hydraulic conductivity of the untreated and nanoparticles-treated residual soils. The soil samples were first prepared at their respective optimum moisture content determined from the standard Proctor test and cured for $24 \mathrm{~h}$. Then, the cured samples were compacted in a rigid wall compaction mold and mounted to the falling head permeameter connected to a standpipe. The samples were allowed to saturate for a minimum period of one week by allowing water to flow from the reservoir to the remolded samples in the compaction molds. Full saturation was confirmed by the water outflow coming through the outlets of the compaction permeameters. This long saturation process was applied to ensure the complete saturation of the specimens prior to taking the first set of readings. During saturation, the specimens were restrained vertically from swelling. This means that all samples maintained their initial dry unit weight throughout the saturation process. Permeation of the samples for the hydraulic conductivity test continued until flow stabilization, and the termination criteria specified in [27] were met (i.e., when there was no significant change in hydraulic conductivity over time). The hydraulic conductivity measurements were taken consecutively for seven weeks to observe the long-term hydraulic performance of the untreated and treated soil samples. Equation (3) was used to determine the hydraulic conductivity of the soil samples:

$$
k=\frac{a L}{A t} \ln \frac{h_{1}}{h_{2}}
$$


where $k=$ hydraulic conductivity $(\mathrm{cm} / \mathrm{s}) ; a=$ cross-sectional area of the standpipe $\left(\mathrm{cm}^{2}\right) ; L=$ length of specimen (cm); $A=$ cross-sectional area of the mounted sample; $h_{1}=$ head loss across the soil specimen $\mathrm{t}_{1}(\mathrm{~cm}) ; h_{2}=$ head loss across the soil specimen $\mathrm{t}_{2}(\mathrm{~cm}) ;$ and $t=$ time period between $h_{1}$ and $h_{2}$.

\subsubsection{Unconfined Compressive Strength (UCS)}

The unconfined compressive strength (UCS) of untreated and nanoparticles-treated residual soils was determined according to the procedure outlined in [28]. The soil samples were first prepared at optimum moisture content and compacted in three layers with 27 blows in each layer using the standard compaction technique. After compaction, the samples were removed from the compaction mold using an extruder and kept in sealed plastic bags by wrapping in low-density polyethene film. Triplicate samples were prepared for each untreated and treated soil sample to ensure the consistency of the results. Then, the prepared samples were cured for one, seven, and 14 days to study their strength variation with curing time. The compacted samples were loaded with an automated data acquisition unit at an axial rate of $1 \%$ per minute until the applied load values decreased with increasing strain. The UCS of each sample was calculated based on the maximum applied load value.

\subsection{Microstructural Tests}

Microstructural tests such as X-ray diffraction (XRD), variable-pressure scanning electron microscopy (VP-SEM), and energy-dispersive X-ray spectroscopy (EDX) were carried out on untreated and treated soil samples cured after 14 days. The purpose of performing microstructural tests is to explore the changes in mineralogy, morphology, and elemental composition of the residual soil samples after treating it with calcium and magnesium hydroxide nanoparticles.

\subsubsection{X-ray Diffraction (XRD)}

X-ray diffraction $(\mathrm{XRD})$ tests were conducted on untreated and treated soil samples using a Bruker D8-Focus diffractometer to determine the mineralogical composition and the formation of any new minerals. The air-dried samples for untreated and treated soil samples cured after 14 days were grinded to powder form before performing the XRD tests. The samples were scanned using a CuK $\alpha$ radiation at an angle of $2 \theta$ ranging from $5^{\circ}$ to $90^{\circ}$ with a step size of $0.03^{\circ} / \mathrm{min}$. The minerals present in the soil structure were then identified by performing analysis using DIFFRAC.EVA software.

\subsubsection{Variable-Pressure Scanning Electron Microscope (VP-SEM) and Energy-Dispersive X-ray Spectroscopy (EDX)}

The air-dried samples for untreated and treated soil samples cured after 14 days were fractured to obtain relatively small soil chunks before performing the VP-SEM and EDX tests. The fractured samples were attached to sample holders using adhesive carbon tape before transferring the samples to the Quorum/Q140RS Sputter coater, where the samples were sputtered and platinum coated for a time period of $40 \mathrm{~s}$. The platinum coating enhances the electrical conductivity of the soil sample surface and resists any build-up charges. Then, the images of the samples were captured using the Hitachi S-3400N Scanning Electron Microscope operating at a voltage of $5 \mathrm{kV}$ with an emission current of $64 \mathrm{uA}$. The EDX analyses were performed to identify the elemental changes that occurred on the treated soil samples after the soil stabilization process. The EDX analyses were conducted with a Horiba X-Max detector operating at a voltage of $5000 \mathrm{~V}$ and a current of $9400 \mathrm{nA}$.

\subsection{Statistical Analysis}

One-way ANOVA was employed to study the effects of magnesium and calcium hydroxide nanoparticles treatments on the UCS development at a significance level of 0.05 using Origin (Version 8.0) software package. The curing duration (one, seven, and 14 days) were considered as a block effect, and the soil stabilization methods (untreated, magnesium, and calcium hydroxide nanoparticles-treated 
soil) as treatment. Then, Fisher's least significant difference method was utilised to distinguish significant difference between means.

\section{Results and Discussions}

\subsection{Effect of Nanoparticles on Atterberg Limits}

Table 1 depicts the influence of nanoparticles on the Atterberg limits of the residual soil. Results showed that the liquid limit and plastic limit of residual soils treated with two different nanoparticles decreased; thus, the plasticity index, which is the difference between the liquid limit and plastic limit, also decreased. The changes in the Atterberg limits with the addition of nanoparticles can be related to the diffuse double layer (DDL) theory. After mixing the residual soils with the solutions containing the nanoparticles precipitates, the divalent calcium and magnesium cations were attached to the negatively charged clay surface and displaced other monovalent ions such as the hydrogen ions from the water molecules. In addition, the presence of divalent calcium and magnesium cations increases the electrolyte concentration of pore fluid, leading to a reduction in the DDL thickness. As a result, the Atterberg limits of treated soils decreased due to the reduction in DDL thickness. The reduction in Atterberg limits of treated soils led to the transition of soil plasticity classification from high plasticity clay to intermediate plasticity clay. This transition indicates an improvement in the workability of soil, making the soil easier to compact [12].

Table 1. Atterberg limits of the untreated and nanoparticles-treated residual soil samples.

\begin{tabular}{cccc}
\hline Property & Natural Soil (NS) & $\begin{array}{c}\text { Calcium Hydroxide } \\
\text { Treated Soil (CS) }\end{array}$ & $\begin{array}{c}\text { Magnesium Hydroxide } \\
\text { Treated Soil (MS) }\end{array}$ \\
\hline Liquid limit (\%) & 50.10 & 46.00 & 41 \\
Plastic limit (\%) & 21.80 & 20.35 & 19.65 \\
Plasticity index (\%) & 28.30 & 23.85 & 21.35 \\
British Standard (BS) Soil & $\mathrm{CH}$ & $\mathrm{CI}$ & $\mathrm{CI}$ \\
Classification System & & & \\
\hline
\end{tabular}

\subsection{Effect of Nanoparticles on Compaction Characteristics}

The compaction characteristics of untreated and nanoparticles-treated residual soils are shown in Figure 2. The maximum dry density (MDD) recorded for natural soil (NS) was $1.828 \mathrm{~kg} / \mathrm{m}^{3}$. With the presence of magnesium hydroxide nanoparticles, the MDD increased to $1.837 \mathrm{~kg} / \mathrm{m}^{3}$. However, the MDD decreased to $1.794 \mathrm{~kg} / \mathrm{m}^{3}$ for soil samples treated with calcium hydroxide nanoparticles. The optimum moisture content (OMC) of NS had a value of $18 \%$, and upon treatment with calcium and magnesium hydroxide nanoparticles, the OMC of the treated soils reduced to $17.1 \%$ and increased to $19.3 \%$, respectively. This observation shows that the presence of magnesium and calcium hydroxide nanoparticles have different impacts on the compaction characteristics of residual soils. The increment in MDD and reduction in OMC of magnesium hydroxide nanoparticles-treated soil (MS) can be related to the decreased thickness of DDL around the soil particles due to the presence of divalent magnesium cations. The reduced thickness of DDL led to lower attraction of water molecules; thus, this contributes to the reduction in the OMC and increment in MDD of MS. The compaction characteristics of calcium hydroxide treated residual soils (CS) exhibited a different trend whereby their MDD decreased accompanied by increased OMC. Similar trends were reported by $[29,30]$ that adopted calcium-based additives in the stabilization of residual soils. It is quite likely that the pozzolanic reactions between the soil and calcium ions led to a higher accumulation of water molecules around the soil particles [31]. This situation resulted in an increased OMC of CS, causing large water films developed around the soil particles. The presence of large water films prevents the closer packing of soil particles and reduces their MDD as observed. 


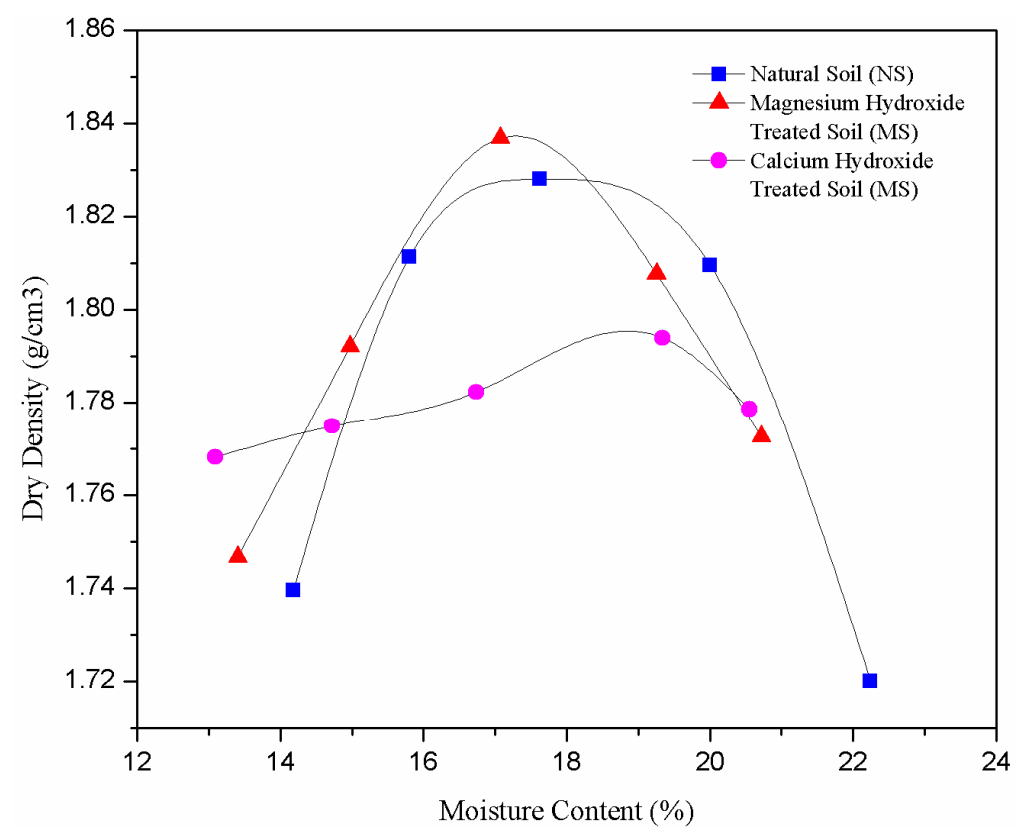

Figure 2. Compaction curves for untreated and nanoparticles-treated soil specimens.

\subsection{Effect of Nanoparticles on Hydraulic Conductivity}

Figure 3 displays the relationship between hydraulic conductivity over permeation time for untreated and nanoparticles-treated soil samples. It is observed that the hydraulic conductivity of untreated and treated samples decreased with testing duration. The hydraulic conductivity of NS decreased from $4.96 \times 10^{-7} \mathrm{~cm} / \mathrm{s}$ to $1.26 \times 10^{-7} \mathrm{~cm} / \mathrm{s}$ after seven weeks of testing. It is quite likely that after long-term permeation, the voids between the soil particles are fully occupied by the water molecules. As a result, the movement of water along the compacted soil samples slows down and reduces the hydraulic conductivity of NS. The hydraulic conductivity of nanoparticles-blended soil reduced to almost one order of magnitude after seven weeks of permeation. The percentage reduction of the hydraulic conductivity values after seven weeks of permeation for the magnesium and calcium hydroxide nanoparticles-treated samples relative to the first week were approximately $81 \%$ and $99 \%$, respectively. The observed percentage reduction in the hydraulic conductivity of nanoparticles-treated soils was more significant than that of untreated soil $(75 \%)$. This variation can be due to the clogging of soil pores by the formation of cementing gels from the reactions between magnesium and calcium nanoparticles and the soil matrix. Among the two nanoparticles-treated samples, CS showed better hydraulic performance compared to MS, as evident by their percentage reductions. This phenomenon can be attributed to the effectiveness of the cementing gels formed for the CS relative to the MS. Likewise, the higher OMC of CS compared to MS provides a more convoluted flow path for water to follow. Consequently, a further decrease in the hydraulic conductivity was observed. It is interesting to note that the recorded hydraulic conductivity values for the treated soil specimens satisfied the permeability requirements for landfill liner materials $\left(\leq 1 \times 10^{-7} \mathrm{~cm} / \mathrm{s}\right)$ specified by [32-34]. 


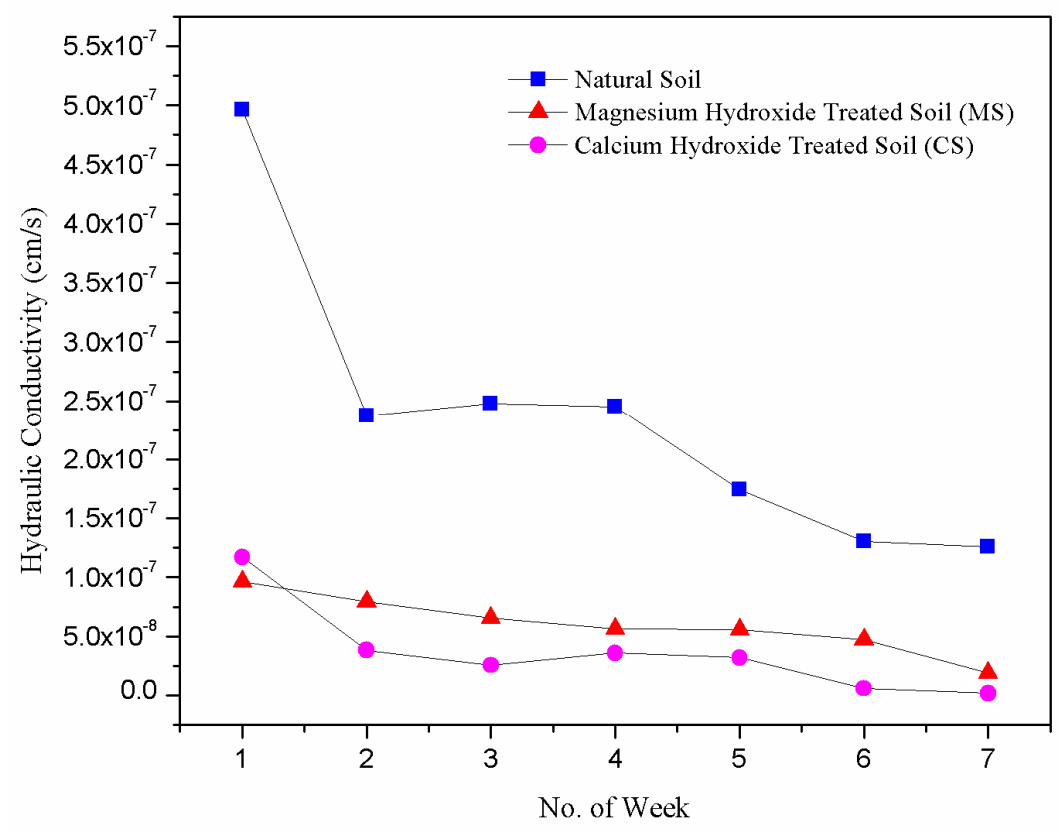

Figure 3. Variations of hydraulic conductivity for untreated and nanoparticles-treated soil specimens over permeation time.

\subsection{Effect of Nanoparticles on Unconfined Compressive Strength (UCS)}

The variation of the UCS for the untreated and treated soil specimens after one, seven, and 14 days of curing are demonstrated in Figure 4. It is observed that the UCS for the treated soils were significantly greater than that of the untreated soil at the various curing duration. It is also noted that the treated soil samples experienced a gain in strength with increasing curing duration. The improvement in the strength of MS and CS at a shorter curing period is associated with the flocculation/agglomeration of soil particles due to the cation exchange process that led to reduced DDL thickness. The flocculation of soil particles increases the effective grain size, and thus increases the contact between the soil particles, and hence resulted in the enhanced strength of the compacted soil. At a longer curing period, the increase in the UCS can be attributed to the formation of cementing gels, including magnesium silicate hydrate (M-S-H), magnesium aluminate hydrate (M-A-H), calcium silicate hydrate (C-S-H), and calcium aluminate hydrate $(\mathrm{C}-\mathrm{A}-\mathrm{H})$ due to the nanoparticles-soil interaction, which improved the bonding of the soil particles, and consequently increased the UCS of the treated soil [35]. Likewise, the nanoparticles turn to fill the voids of the soils effectively; hence, decreasing the porosity and increasing the particle-particle contact. Consequently, a further increase in the UCS was observed for the treated specimens. It is also observed that the strength improvement of CS was superior to that of MS samples at various curing durations. This strength variation is associated to the smaller hydrated radius of $\mathrm{Ca}^{2+}$ compared to $\mathrm{Mg}^{2+}\left(0.412 \mathrm{~nm}\right.$ for $\mathrm{Ca}^{2+}$ versus $0.428 \mathrm{~nm}$ for $\left.\mathrm{Mg}^{2+}\right)$ [36], leading to stronger electrostatic attraction between $\mathrm{Ca}^{2+}$ and the negatively charged clay. It is reported that a smaller hydrated radius will have weaker hydration capability due to its lower affinity to the water molecules; hence, contributing to the higher retention of the $\mathrm{Ca}^{2+}$ on the clay surface [37]. This phenomenon inevitably triggers the higher rate of formation of cementing gels, particularly C-S- $\mathrm{H}$ and C-A-H, causing the superior performance of CS compared to MS. In fact, the UCS of MS (241 kPa) and CS (276 kPa) after 7 days of curing were superior to the UCS reported by [38,39] that performed investigations on the residual soils treated with (i) potassium hydroxide and untreated coir fibers $(170 \mathrm{kPa})$, (ii) potassium hydroxide and treated coir fibers $(230 \mathrm{kPa})$, and (iii) rice husk ash $(150 \mathrm{kPa})$ at the same curing period. 


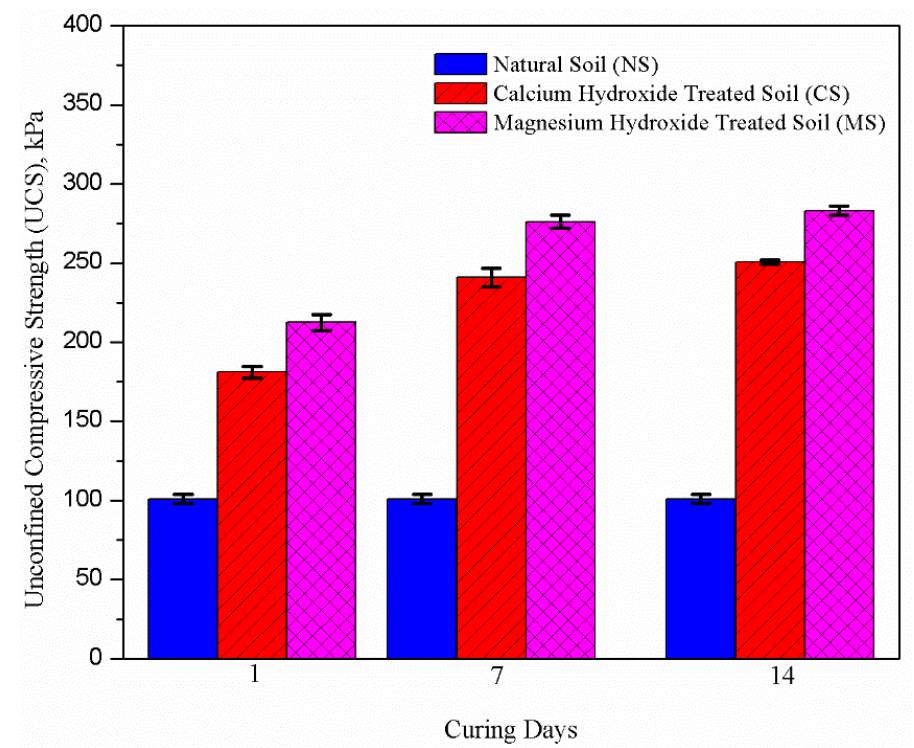

Figure 4. The unconfined compressive strength for untreated and nanoparticles-treated soil specimens subjected to one, seven, and 14 days of curing.

Table 2 summarizes the results of one-way ANOVA for untreated and treated soil specimens based on their respective UCS at different curing periods. As observed from Table 2, the calculated P value 0.00201 is smaller than the significance level of 0.05 . This implies that the soil stabilization methods (untreated soil and treated soils with calcium and magnesium hydroxide particles) have significant impact on the mean UCS at different curing periods (one, seven, and 14 days). Since the ANOVA analyses show significant differences due to treatment methods, the mean UCS for untreated and treated soils were further compared by adopting Fisher's least significant difference method, and the results of the analysis are provided in Table 3. It is clearly noticed that the mean difference between treated soils with calcium or magnesium hydroxide nanoparticles and untreated soil are statistically significant at a significance level of 0.05 . Hence, it can be concluded that the soil treatment methods using calcium hydroxide and magnesium hydroxide nanoparticles affects the UCS development of soil samples.

Table 2. One-way ANOVA for untreated and treated soil specimens based on their UCS values.

\begin{tabular}{cccccc}
\hline Source of Variation & Sum of Squares & Degrees of Freedom & Mean Square & F Value & $\boldsymbol{p}$ Value \\
\hline Treatment & $40,656.06$ & 2 & $20,328.03$ & 20.79 & 0.00201 \\
Error & 5866.42 & 6 & 977.74 & & \\
Total & $46,522.48$ & 8 & & & \\
\hline
\end{tabular}

Table 3. Results obtained from Fisher's least significant difference (LSD) analysis.

\begin{tabular}{cccccc}
\hline $\begin{array}{c}\text { Comparison between Treatment } \\
\text { Methods }\end{array}$ & $\begin{array}{c}\text { Mean } \\
\text { Difference }\end{array}$ & $\begin{array}{c}\text { Standard Error } \\
\text { of Mean }\end{array}$ & $\begin{array}{c}\mathbf{t} \\
\text { Value }\end{array}$ & Alpha & Significant \\
\hline $\begin{array}{c}\text { Calcium hydroxide treated soil (CS) } \\
\text { vs. natural soil (NS) }\end{array}$ & 156.20 & 25.53 & 6.12 & 0.05 & Yes \\
$\begin{array}{c}\text { Magnesium hydroxide treated soil (MS) } \\
\text { vs. natural soil (NS) }\end{array}$ & 123.15 & 25.53 & 4.82 & 0.05 & Yes \\
\hline
\end{tabular}




\subsection{Effect of Nanoparticles on Microstructural Properties}

\subsubsection{X-ray Diffraction (XRD)}

The XRD micrographs for untreated and treated soil samples after 14 days of curing are illustrated in Figure 5. The main minerals identified in the natural and treated soil samples at various $2 \theta$ angles are quartz, kaolinite and illite. A minor reflection of goethite was also observed. Although no major changes occurred in the diffractograms of the treated soil in comparison to the natural soil, the apparent appearance of several new reflections for the treated soil were observed. These reflections are associated with the formation of cementing gels, including calcium silicate hydrate, calcium aluminate hydrate, magnesium silicate hydrate, and magnesium aluminate hydrate due to the reactions of the calcium and magnesium ions with the silicates and aluminates at the soil surface, as shown in Equations (4)-(7) [40].

$$
\begin{aligned}
\mathrm{Ca}^{2+}+\mathrm{OH}^{-}+\text {Soluble Silica } & \rightarrow \text { Calcium Silicate Hydrate }(\mathrm{C}-\mathrm{S}-\mathrm{H}) \\
\mathrm{Ca}^{2+}+\mathrm{OH}^{-}+\text {Soluble Alumina } & \rightarrow \text { Calcium Aluminate Hydrate }(\mathrm{C}-\mathrm{A}-\mathrm{H}) \\
\mathrm{Mg}^{2+}+\mathrm{OH}^{-}+\text {Soluble Silica } & \rightarrow \text { Magnesium Silicate Hydrate }(\mathrm{M}-\mathrm{S}-\mathrm{H}) \\
\mathrm{Mg}^{2+}+\mathrm{OH}^{-}+\text {Soluble Alumina } & \rightarrow \text { Magnesium Aluminate Hydrate }(\mathrm{M}-\mathrm{A}-\mathrm{H})
\end{aligned}
$$

Hence, the formation of these new phases act as binders to improve the bonding between the soil particles, and consequently caused the increased of the UCS of the treated soil samples. The absence of these reflections in the natural soil indicated that the stabilization process was due to the hydration and pozzolanic reactions.

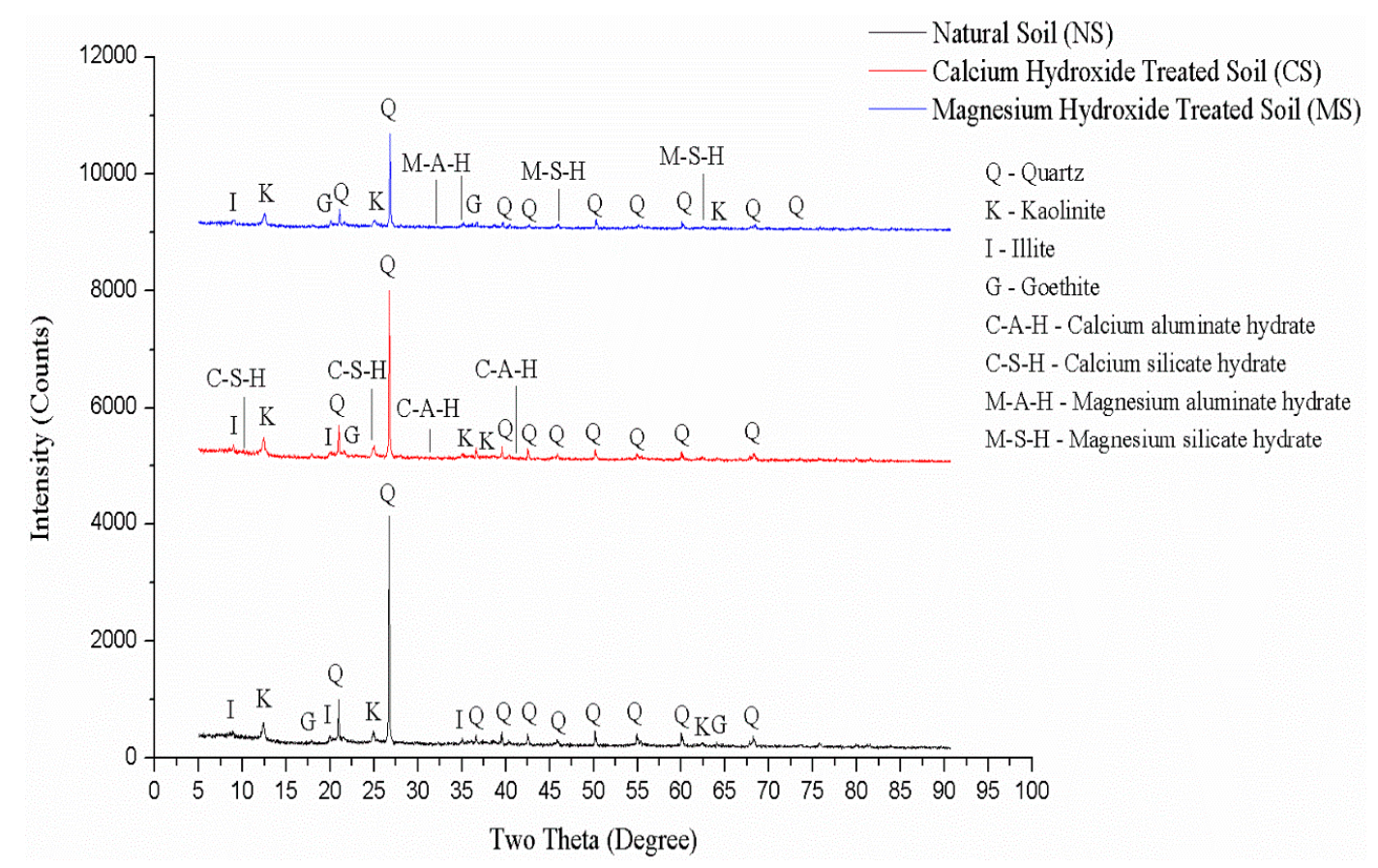

Figure 5. XRD graphs for untreated and nanoparticles-treated residual soils.

\subsubsection{Variable Pressure Scanning Electron Microscope (VP-SEM)}

Figure 6 presents the VP-SEM images for the untreated and treated soil samples after 14 days of curing. It is noticed that the natural soil samples (Figure 6a) showed a dispersed structure with a considerable number of visible voids. At the same magnification scale, both calcium and magnesium hydroxide treated soil samples (Figure $6 \mathrm{~b}, \mathrm{c}$, respectively) exhibited a continuous and dense structure. This observation provides evidence for the improved UCS and reduced hydraulic conductivity of the 
treated soil samples as the combined effects of flocculation and the formation of cementing gels such as calcium silicate hydrate, calcium aluminate hydrate, magnesium silicate hydrate, and magnesium aluminate hydrate enhanced the interlocking of soil particles and resulted in a denser soil structure. In addition, the denser soil structure inevitably restricted the water flow path as the tortuosity of water flow path increases due to reduced soil pores. This behavior is primarily responsible for the lower hydraulic conductivity values obtained for the treated soil samples relative to the natural soil sample.

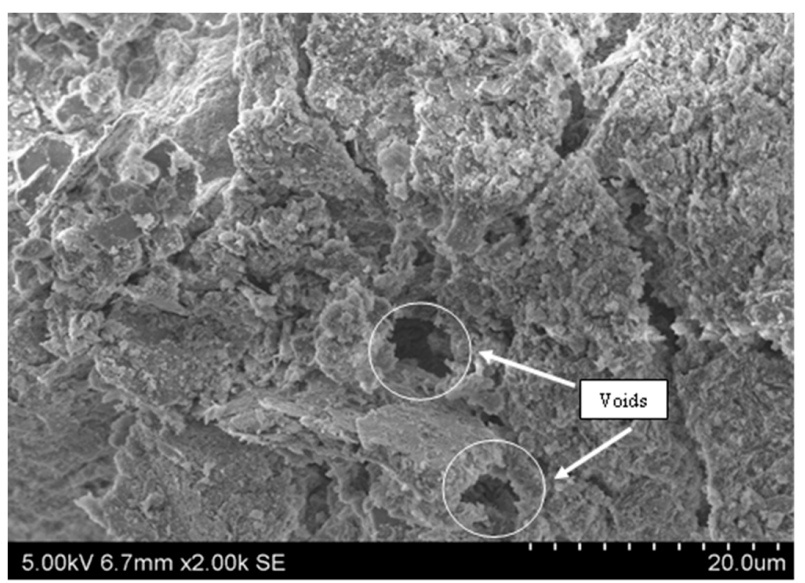

(a)

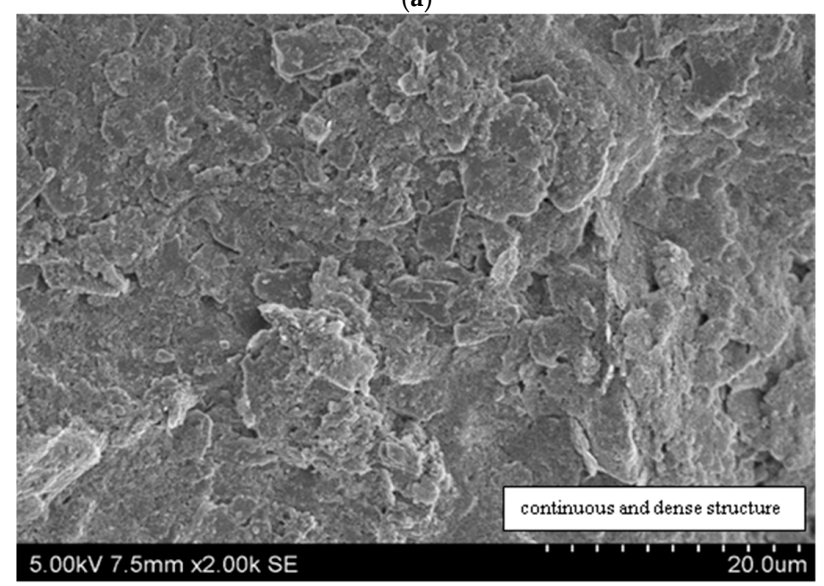

(b)

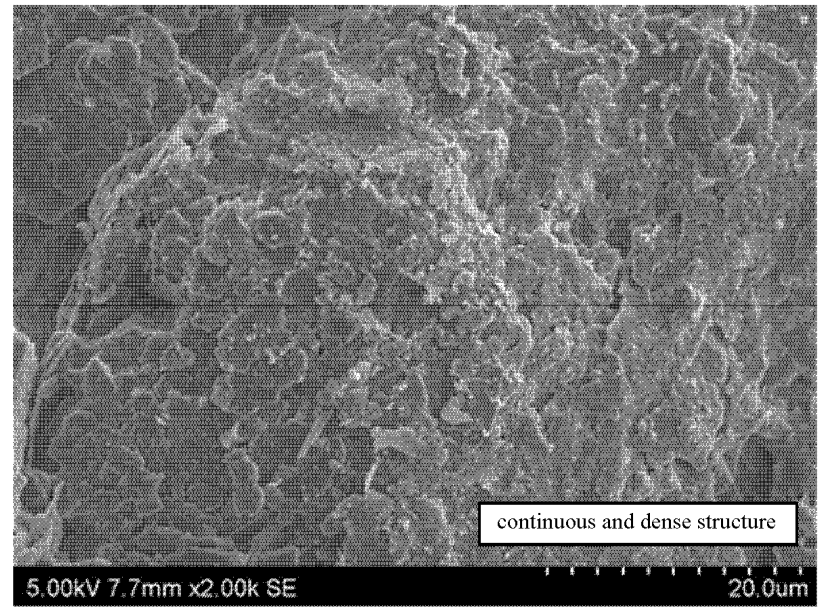

(c)

Figure 6. Variable-pressure scanning electron microscope (VP-SEM) images for untreated and nanoparticles-treated residual soils. (a) Natural soil (NS); (b) calcium hydroxide treated soil (CS); (c) Magnesium hydroxide treated soil (MS). 


\subsubsection{Energy-Dispersive X-ray Spectroscopy (EDX)}

Table 4 summarizes the elemental composition of the natural soils (NS), calcium hydroxide treated soil (CS), and magnesium hydroxide treated soil (MS) after 14 days curing duration. It is observed that relatively high percentages of chemical elements such as aluminum $(\mathrm{Al})$, silicon $(\mathrm{Si})$, and iron $(\mathrm{Fe})$ are commonly present in NS, CS, and MS. This observation is consistent with the nature of tropical residual soils [4]. The presence of carbon $(\mathrm{C})$ and platinum $(\mathrm{Pt})$ in three soil samples are due to the carbon tape that adheres the soil chunks to the sample holder and the coating of the platinum on the surface of the soil chunks prior to VP-SEM examination, respectively. Sodium ( $\mathrm{Na}$ ) and Chloride $(\mathrm{Cl})$ are two chemical elements formed as residues from the chemical reactions depicted in Equation (1). However, their percentages are relatively low; hence, their presence in the CS and MS showed negligible effects on the soil properties. In addition, the availability of calcium (Ca) and magnesium $(\mathrm{Mg})$ in CS and MS, respectively, confirmed the presence of calcium and magnesium ions in the treated soil samples to facilitate the hydration and pozzolanic reactions. Similarly, the changes in the Al:Si ratio for the CS and MS as summarized in Table 4 can be attributed to the possible formation of C-A-H, C-S-H, M-A-H, and M-S-H, as observed from the XRD diffractograms of treated soil samples $[4,35]$.

Table 4. Elemental compositions of treated and untreated soils after 14 days curing time.

\begin{tabular}{cccc}
\hline Elements & Natural Soil, NS (\%) & $\begin{array}{c}\text { Calcium Hydroxide } \\
\text { Treated Soil, CS (\%) }\end{array}$ & $\begin{array}{c}\text { Magnesium Hydroxide } \\
\text { Treated Soil, MS (\%) }\end{array}$ \\
\hline $\mathrm{C}$ & 10.74 & 11.96 & 10.23 \\
$\mathrm{O}$ & 61.91 & 61.20 & 59.67 \\
$\mathrm{Al}$ & 10.34 & 9.71 & 10.50 \\
$\mathrm{Si}$ & 12.85 & 11.41 & 12.61 \\
$\mathrm{Fe}$ & 1.09 & 1.12 & 3.40 \\
$\mathrm{Pt}$ & 3.08 & 3.01 & 2.56 \\
$\mathrm{Ca}$ & - & 1.01 & - \\
$\mathrm{Mg}$ & - & - & 0.46 \\
$\mathrm{Na}$ & - & 0.25 & 0.25 \\
$\mathrm{Cl}$ & - & 0.32 & 0.32 \\
$\mathrm{Al} / \mathrm{Si}$ & 0.80 & 0.85 & 0.83 \\
\hline
\end{tabular}

\section{Conclusions}

A series of laboratory investigations were conducted to explore the effects of calcium hydroxide and magnesium hydroxide particles on the geotechnical and microstructural properties of the residual soils. The following conclusions are summarized based on the results obtained:

1. The Atterberg limits of both treated soil samples reduced as a result of decreased DDL thickness. The change in the Atterberg limits caused a transition in soil plasticity classification from high plasticity clay $(\mathrm{CH})$ to intermediate plasticity clay $(\mathrm{CI})$.

2. Calcium hydroxide and magnesium hydroxide nanoparticles showed different effects on the compaction characteristics of the treated soil samples. The MDD of CS decreased with increased OMC due to the pozzolanic reactions between the soil and calcium ions. The compaction characteristics of MS portrayed a different trend whereby their MDD decreased with increased OMC as a result of reduced DDL thickness.

3. The hydraulic conductivity of calcium and magnesium hydroxide nanoparticles-treated samples reduced significantly with permeation time. This is probably due to the clogging of soil pores by the cementing gels formed. These phenomena retarded the movement of water along the compacted soil matrix and resulted in lower hydraulic conductivity.

4. The UCS of nanoparticles-treated samples increased with increasing curing time due to enhanced interlocking between the soil particles. It is quite likely that the flocculation of soil particles 
and the formation of cementing gels enhanced the bonding of the soil particles and gave rise to a denser soil structure.

5. The appearance of denser and compacted soil structure as shown in the VP-SEM images of CS and MS justified the explanation of the reduced hydraulic conductivity and increased UCS of treated soil samples. In addition, the formation of new cementing gels such as calcium silicate hydrate, calcium aluminate hydrate, magnesium silicate hydrate, and magnesium aluminate hydrate, which act as soil binders, were observed from the XRD analysis of treated soil samples.

In conclusion, magnesium hydroxide and calcium hydroxide nanoparticles produced from the quick precipitation method can be utilized as environmental-friendly stabilizers in improving the geotechnical properties of poor soils. Nonetheless, the calcium hydroxide treated sample showed better performance compared to the magnesium hydroxide treated sample in terms of lower hydraulic conductivity and higher UCS.

Author Contributions: Conceptualization, V.A. and L.L.Y.; Methodology, L.L.Y. and E.E.; Investigation, L.L.Y. and S.V.A.D.N.J.P.; Resources, V.A.; Data Curation, L.L.Y. and S.V.A.D.N.J.P.; Writing-Original Draft Preparation, L.L.Y. and S.V.A.D.N.J.P.; Writing-Review and Editing, E.E.; A.S.; S.C.P. and V.A.; Visualization, L.L.Y. and V.A.; Supervision, A.S.; S.C.P. and V.A.; Project Administration, A.S. and S.C.P.; Funding Acquisition, V.A.

Funding: This research was funded by Ministry of Higher Education in Malaysia, grant number FRGS/1/2017/TK01/MUSM/03/01. This support is gratefully acknowledged.

Conflicts of Interest: The authors declare no conflict of interest.

\section{Nomenclature}

C-A-H calcium aluminate hydrates

CS calcium hydroxide treated soil

C-S-H calcium silicate hydrates

DDL diffuse double layer

EDX energy-dispersive $x$-ray spectroscopy

M-A-H magnesium aluminate hydrate

MS magnesium hydroxide treated soil

M-S-H magnesium silicate hydrate

MDD maximum dry density

NS natural soil

OMC optimum moisture content

UCS unconfined compressive strength

VP-SEM variable-pressure scanning electron microscope

XRD X-ray diffraction

\section{References}

1. Tan, B.K. Country case study: Engineering geology of tropical residual soils in Malaysia. In Tropical Residual Soils Engineering; Huat, B.B.K., Gue, S.S., Ali, F.H., Eds.; Taylor \& Francis Group: London, UK, 2004; pp. 237-243.

2. Taha, M.R.; Kabir, M.H. Tropical residual soil as compacted soil liners. Environ. Geol. 2004, 47, 375-381. [CrossRef]

3. Singh, H.; Jotisankasa, A.; Huat, B.B.K. Residual soils of southeast asia. In Handbook of Tropical Residual Soils Engineering; Huat, B.B.K., Toll, D.G., Prasad, A., Eds.; CRC Press: New York, NY, USA, 2013; pp. 491-532.

4. Latifi, N.; Eisazadeh, A.; Marto, A.; Meehan, C.L. Tropical residual soil stabilization: A powder form material for increasing soil strength. Constr. Build. Mater. 2017, 147, 827-836. [CrossRef]

5. Rashid, A.S.A.; Latifi, N.; Meehan, C.L.; Manahiloh, K.N. Sustainable Improvement of Tropical Residual Soil Using an Environmentally Friendly Additive. Geotech. Geol. Eng. 2017, 35, 2613-2623. [CrossRef]

6. Behnood, A. Soil and clay stabilization with calcium- and non-calcium-based additives: A state-of-the-art review of challenges, approaches and techniques. Transp. Geotech. 2018, 17, 14-32. [CrossRef] 
7. Gu, K.; Jin, F.; Al-Tabbaa, A.; Shi, B.; Liu, C.; Gao, L. Incorporation of reactive magnesia and quicklime in sustainable binders for soil stabilisation. Eng. Geol. 2015, 195, 53-62. [CrossRef]

8. Kafodya, I.; Okonta, F. Effects of natural fiber inclusions and pre-compression on the strength properties of Lime-Fly ash stabilised soil. Constr. Build. Mater. 2018, 170, 737-746. [CrossRef]

9. Ayeldeen, M.; Kitazume, M. Using fiber and liquid polymer to improve the behaviour of Cement-Stabilized soft clay. Geotext. Geomembr. 2017, 45, 592-602. [CrossRef]

10. Consoli, N.C.; Arcari Bassani, M.A.; Festugato, L. Effect of Fiber-Reinforcement on the strength of cemented soils. Geotext. Geomembr. 2010, 28, 344-351. [CrossRef]

11. Iranpour, B.; Haddad, A. The influence of nanomaterials on collapsible soil treatment. Eng. Geol. 2016, 205, 40-53. [CrossRef]

12. Emmanuel, E.; Lau, C.C.; Anggraini, V.; Pasbakhsh, P. Stabilization of a soft marine clay using halloysite nanotubes: A Multi-Scale approach. Appl. Clay Sci. 2019, 173, 65-78. [CrossRef]

13. Changizi, F.; Haddad, A. Strength properties of soft clay treated with mixture of nano-SiO 2 and recycled polyester fiber. J. Rock Mech. Geotech. Eng. 2015, 7, 367-378. [CrossRef]

14. Coo, J.L.; So, Z.P.S.; Ng, C.W.W. Effect of nanoparticles on the shrinkage properties of clay. Eng. Geol. 2016, 213, 84-88. [CrossRef]

15. Alsharef, J.M.A.; Taha, M.R.; Firoozi, A.A.; Govindasamy, P. Potential of using nanocarbons to stabilize weak soils. Appl. Environ. Soil Sci. 2016, 2016, 1-9. [CrossRef]

16. Naval, S.; Chandan, K.; Sharma, D. Stabilization of expansive soil using nanomaterials. In Proceedings of the International Interdisciplinary Conference on Science Technology Engineering Management Pharmacy and Humanities, Singapore, 22-23 April 2017.

17. Ealias, A.M.; Saravanakumar, M.P. A review on the classification, characterisation, synthesis of nanoparticles and their application. IOP Conf. Ser. Mater. Sci. Eng. 2017, 263, 1-15.

18. Anggraini, V.; Asadi, A.; Farzadnia, N.; Jahangirian, H.; Huat, B.B.K. Effects of coir fibres modified with $\mathrm{Ca}(\mathrm{OH}) 2$ and $\mathrm{Mg}(\mathrm{OH}) 2$ nanoparticles on mechanical properties of lime-treated marine clay. Geosynth. Int. 2016, 23, 206-218. [CrossRef]

19. Shahmiri, M.; Ibrahim, N.A.; Shayesteh, F.; Asim, N.; Motallebi, N. Preparation of PVP-Coated copper oxide nanosheets as antibacterial and antifungal agents. J. Mater. Res. 2013, 28, 3109-3118. [CrossRef]

20. Wu, R.; Ma, Z.; Gu, Z.; Yang, Y. Preparation and characterization of $\mathrm{CuO}$ nanoparticles with different morphology through a simple quick-precipitation method in DMAC-Water mixed solvent. J. Alloy. Compd. 2010, 504, 45-49. [CrossRef]

21. Zhu, J.; Li, D.; Chen, H.C.; Yang, X.; Lu, L.; Wang, X. Highly dispersed CuO nanoparticles prepared by a novel Quick-Precipitation method. Mater. Lett. 2004, 58, 3324-3327. [CrossRef]

22. Jahangirian, H.; Ismail, M.H.S.; Haron, M.J.; Rafiee-Moghaddam, R.; Shameli, K.; Hosseini, S.; Kalantari, K.; Khandanlou, R.; Gharibshahi, E.; Soltaninejad, S. Synthesis and characterization of zeolite/ $\mathrm{Fe}_{3} \mathrm{O}_{4}$ nanocomposite by green quick precipitation method. Dig. J. Nanomater. Biostruct. 2013, 8, 1405-1413.

23. Khandanlou, R.; Ahmad, M.; Shameli, K.; Kalantari, K. Synthesis and characterization of rice straw $/ \mathrm{Fe}_{3} \mathrm{O}_{4}$ nanocomposites by a quick precipitation method. Molecules 2013, 18, 6597-6607. [CrossRef]

24. Anggraini, V.; Asadi, A.; Farzadnia, N.; Jahangirian, H.; Huat, B.B.K. 2016b Reinforcement benefits of nanomodified coir fiber in Lime-Treated marine clay. J. Mater. Civ. Eng. 2016, 28, 1-8. [CrossRef]

25. Malaysia Ministry of Natural Resources and Environment. Geological Map, Map. Scale 1: 63360; DirectorGeneral Minerals and Geoscience Department: Kuala Lumpur, Malaysia, 2010.

26. BS 1377:1990. Methods of Test for Soils for Civil Engineering Purposes; British Standards Institution: London, UK, 1990.

27. ASTM D5856-15. Standard Test Method for Measurement of Hydraulic Conductivity of Porous Material Using a Rigid-Wall, Compaction-Mold Permeameter; ASTM International: West Conshohocken, PA, USA, 2007.

28. ASTM D2166. Standard Test Method for Unconfined Compressive Strength of Cohesive Soil; ASTM International: West Conshohocken, PA, USA, 2005.

29. Amadi, A.A.; Okeiyi, A. Use of quick and hydrated lime in stabilization of lateritic soil: Comparative analysis of laboratory data. Int. J. Geo-Eng. 2017, 8, 1-13. [CrossRef]

30. Di Sante, M.; Fratalocchi, E.; Mazzieri, F. Effects of variation in compaction water content on geotechnical properties of Lime-Treated clayey soil. Procedia Eng. 2016, 158, 63-68. [CrossRef] 
31. Jha, A.K.; Sivapullaiah, P.V. Mechanism of improvement in the strength and volume change behavior of lime stabilized soil. Eng. Geol. 2015, 198, 53-64. [CrossRef]

32. Daniel, D.E. (Ed.) Clay liners. In Geotechnical Practice for Waste Disposal; Chapman \& Hall: London, UK, 1993; pp. 137-163.

33. Rowe, R.K.; Quigley, R.M.; Brachman, R.W.I. Barrier Systems for Waste Disposal, 2nd ed.; Spon Press: New York, NY, USA, 2004.

34. USEPA. Requirements for Hazardous Waste Landfill Design, Construction and Closure; USEPA: Cincinnati, $\mathrm{OH}$, USA, 1989.

35. Emmanuel, E.; Anggraini, V.; Raghunandan, M.E.; Asadi, A.; Bouazza, A. Improving the engineering properties of a soft marine clay with forsteritic olivine. Eur. J. Environ. Civ. Eng. 2019, 1-28. [CrossRef]

36. Volkov, A.G.; Paula, S.; Deamer, D.W. Two mechanisms of permeation of small neutral molecules and hydrates ions across phospholipid bilayers. Bioelectroch. Bioenerg. 1997, 42, 153-160. [CrossRef]

37. Xue, Q.; Li, J.; Liu, L. Experimental study on Anti-Seepage grout made of leachate contaminated clay in landfill. Appl. Clay Sci. 2013, 80-81, 438-442. [CrossRef]

38. Tan, T.; Huat, B.B.K.; Anggraini, V.; Shukla, S.K. Improving the engineering behaviour of residual soil with fly ash and treated natural fibres in alkaline condition. Int. J. Geotech. Eng. 2019, 1-14. [CrossRef]

39. Basha, E.A.; Hashim, R.; Mahmud, H.B.; Muntohar, A.S. Stabilization of residual soil with rice husk ash and cement. Constr. Build. Mater. 2005, 19, 448-453. [CrossRef]

40. Firoozi, A.A.; Guney Olgun, C.; Firoozi, A.A.; Baghini, M.S. Fundamentals of soil stabilization. Int. J. Geo-Eng. 2017, 8, 1-16. [CrossRef]

(C) 2019 by the authors. Licensee MDPI, Basel, Switzerland. This article is an open access article distributed under the terms and conditions of the Creative Commons Attribution (CC BY) license (http://creativecommons.org/licenses/by/4.0/). 